ISSN: $2317-8957$

Volume 6, Number 1, Jun. 2018

\title{
CHARACTERIZATION OF POLYPROPYLENE POST-CONSUME / BANANA FIBER COMPOSITES
}

\author{
ARIADNE GONÇALVES DE LEÃO ${ }^{1}$, PATRICIA SOARES DA COSTA PEREIRA ${ }^{1}$, DANIELE CRUZ BASTOS ${ }^{1}$, \\ ${ }^{1}$ Fundação Centro Universitário Estadual da Zona Oeste (UEZO), Avenida Manuel Caldeira de Alverenga, 1203, Campo Grande, Rio de Janeiro, \\ $\mathrm{Rj}$, Brasil.
}

\begin{abstract}
In this study, banana fibre surfaces were chemically modified and composites using polypropylene as a matrix were prepared. The FTIR analysis confirmed that the esterification increased the crystallinity and thermal stability of the acetylated fibres. Composites showed a decrease in the melt flow index and a slight reduction in density and hardness in relation to the matrix. Good matrix/fibre adhesion was observed by SEM micrographs.
\end{abstract}

Keywords: Adhesion, Banana Fibres, Esterification, Polypropylene.

\section{RESUMO}

Neste estudo, superfícies de fibras de bananeira foram quimicamente modificadas e compósitos utilizando polipropileno como matriz foram preparados. A análise de FTIR confirmou que a esterificação aumentou a cristalinidade e a estabilidade térmica das fibras acetiladas. Os compósitos mostraram uma diminuição no índice de fluidez e uma ligeira redução na densidade e dureza em relação à matriz. Boa adesão matriz / fibra foi observada por micrografias de MEV.

Palavras-chave: Citocromo P-450, Monitoramento, Poluição, Rio Guandu, Tilapia.

\section{INTRODUÇÃO}

Plastic materials made from petroleum are not biodegradable, but they are relatively easy to recycle. The large amount of disposable polymer materials in the environment has increased the search for alternative pro- cedures for recycling or reuse of these materials (Venkateshwaran and Elayaperumal, 2010; Spinacé and De Paoli, 2000). Reinforcement of polymer matrix composites with natural fibres is being widely used since these naturally occurring fibres are biodegradable, environmentally friendly and inex- 
AS\&T Volume 6, Number 1, Jun 2018

pensive. Because of their distinct advantages, natural fibres can also be used in plastics and packaging industries instead of synthetic fibres. The study of interfacial properties is important to produce high-performance natural fibre composites (Awal et al., 2011). In this study, composite materials were prepared using postconsumed polypropylene (rPP) as a matrix and chemically modified banana fibres as reinforcement in different proportions. The fibres were characterized before and after chemical modification by FTIR, DRX and thermal analysis (TG/ DTG). The main objective was to observe the influence of the modified banana fibres on the composites' properties, such as density, hardness and MFI, and to correlate these results with the composites' morphology, obtained by SEM.

\section{MATERIALS AND METHODS}

The banana fibres were first modified by mercerization using an alkaline solution (sodium hydroxide $1 \% \mathrm{w} / \mathrm{w}$ ). The fibres remained immersed in $\mathrm{NaOH}$ solution for 1 hour. Subsequently, they were washed until neutral $\mathrm{pH}$ and dried at $40 \mathrm{oC}$ for 24 hours. After mercerization, they were acetylated in a solution of acetic anhydride and acetic acid (1.5:1.0\%w). Twenty drops of sulfuric acid for each $500 \mathrm{~mL}$ of solution was added as catalyst. The fibres suspended in the reaction solution were submitted to ultrasonic bath for 3 hours and remained at rest for 24 hours in the solution. Then they were removed, washed in distillated water and left at rest for 24 hours in water. This last step of washing and resting was repeated three times until the solution's $\mathrm{pH}$ was around 5.0. The fibres were then removed from the water and dried at $40 \mathrm{oC}$ until constant weight. They were characterized before and after chemical modification by DRX, TG/ DTG and FTIR. The rPP/fibre mixtures (100:0, 95:5, 90:10, 80:20 and 70:30) were produced in a twin-screw mini-extruder at $60 \mathrm{rpm}, 180 \mathrm{oC}$, for $10 \mathrm{~min}$. The composites were characterized by SEM, density (ASTM D792- 2008), hardness (ASTM D2240-2010) and melt flow index, MFI (ASTM D 1238).

\section{RESULTS AND DISCUSSION}

The FTIR results are shown in Figure 1. The strong absorption at around $3300 \mathrm{~cm}^{-1}$ in all ATR-FTIR spectra is caused by the remaining $\mathrm{OH}$ groups of the fibre constituents. However, there is a reduction of this band as a result of esterification. The peak at around $1740 \mathrm{~cm}^{-1}$ is due to the esterification of the hydroxyl groups, which results in an increased stretching vibration of the carbonyl $(\mathrm{C}=\mathrm{O})$ group present in the ester bonds. The band in the spectrum of untreated fibres near $1740 \mathrm{~cm}^{-1}$ is assigned primarily to the $\mathrm{C}=\mathrm{O}$ stretching vibration of the carboxyl and acetyl groups in the xylan component of hemicelluloses and also to lignin chemical groups. The appearance of the peak at around $1740 \mathrm{~cm}^{-1}$ for the acetylated fibres indicates that the acetyl groups are involved in an ester bond with the hydroxyl groups of the fibres. The peak at around $1600-1640 \mathrm{~cm}^{-1}$ is probably associated with absorbed water in crystalline cellulose. The increase in the intensity of a peak at around $1239 \mathrm{~cm}-1$ was attributed to the $\mathrm{C}-\mathrm{O}$ stretching of the ester carboxyl group (Tserki et al., 2005). The peak at $1239 \mathrm{~cm}-1$ in the untreated fibres is much smaller after alkali treatment. This peak is a C-O stretching of the acetyl group of lignin and is reduced because lignin is partially removed from the fibre surface.

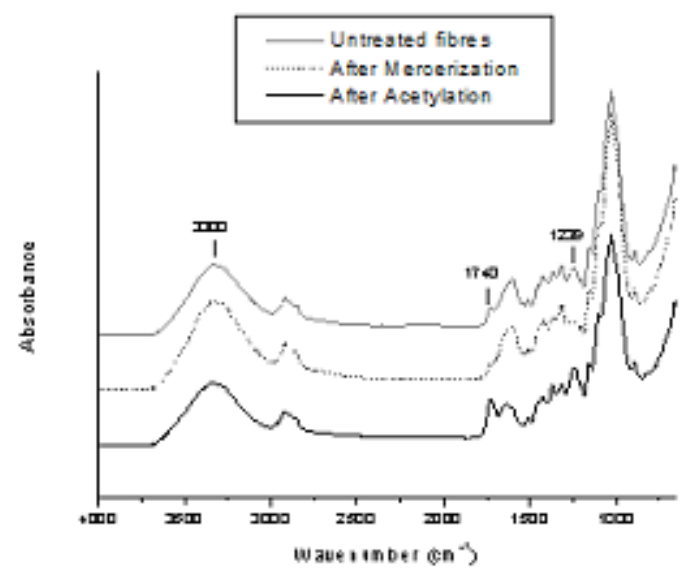

Figura 1. ATR-FTIR spectrum of untreated and treated banana fibres. 
Figure 2 shows the results of DRX analysis. The 16.80 reflection corresponds to the (110) crystallographic plane. The other peak at 22.0o corresponds to the (200) plane (Sgriccia, Hawley, and Misra, 2008). Computer software was used for the deconvolution of the diffractogram to evaluate the crystallinity index (Ic) of the samples by computing the area under the corresponding diffraction peaks (Tanobea et al.,

2005): $\quad I_{C}(\%)=\frac{A_{\text {cristallyne }}}{A_{\text {Total }}} \quad$ Equation 1

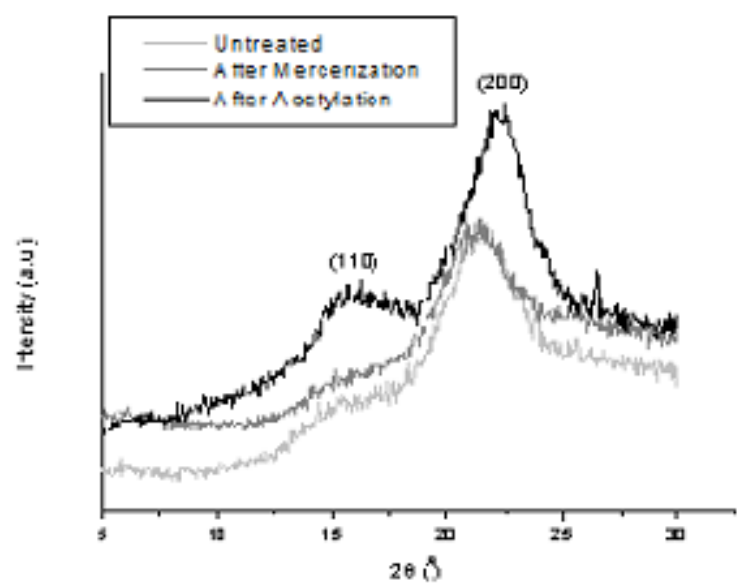

Figure 2. X-ray diffraction patterns of untreated and treated banana fibres.

Acetylated banana fibre has higher crystallinity (Table 1) even though the acetyl groups in the cellulose chains might reduce molecular regularity. This can be reasonably explained by the fact that a small amount of acetyl groups usually softens the cellulose chain and thus facilitates ordered rearrangement of the molecules through a chainfold conformation mechanism (Rong et al.,2001).

Table 1. Crystallinity Index of Banana Fibres.

\begin{tabular}{ll}
\hline Sample & $\begin{array}{l}\text { IC } \\
(\%)\end{array}$ \\
\hline Untreated Fibres & 67.78 \\
After & 71.13 \\
Mercerization & \\
After Acetylation & 71.32 \\
\hline
\end{tabular}

The TG/DTG results are summarized in Table 2. Independently of the chemical treatment, the treated fibres degraded in three steps, similar to the untreated fibres. The initial (onset) and final temperatures of degradation for mercerized fibres were lower than those for untreated fibres, indicating that alkali treatment decreases the thermal stability of fibres. This decrease could be attributed to the exposure of a greater surface area on the mercerized fibres, as reported by Chattopadhyay et al. (2010). The improvement in thermal stability for acetylated fibres is due to the esterification of the hydroxyl groups, as seen by FTIR.

Table 2. Thermal Analysis of Banana Fibres.

\begin{tabular}{|c|c|c|c|c|}
\hline Sample & $T_{\text {tenial }}\left({ }^{\circ} \mathrm{C}\right)$ & $T_{\text {fiat }}\left({ }^{\circ} \mathrm{C}\right)$ & $T_{\operatorname{mix}}(C)$ & Residue (wt\%) \\
\hline Untreated & 236 & 399 & $210 / 355$ & 17 \\
\hline $\begin{array}{l}\text { After } \\
\text { Mercerization }\end{array}$ & 221 & 356 & 329 & 22 \\
\hline $\begin{array}{l}\text { Afler } \\
\text { Acetylation }\end{array}$ & 252 & 405 & $274 / 363$ & 14 \\
\hline
\end{tabular}

Figure 3 shows micrographs of typical fracture surfaces $\mathrm{rPP} /$ fibres obtained by SEM. Virtually no pull-out can be observed, indicating high matrix/fibre interfacial adhesion for composites prepared with up to $30 \%$ fibres. Table 3 summarizes the results obtained for density, hardness and MFI for rPP and composites. The hardness of rPP is higher than a hardness of composites. Thus, the hardness of composites is determined mainly by the thermoplastic phase. Only a small contribution is made by the fibres' domains. The density is slightly increased with the fibres' inclusion, which can be attributed to good matrix/fibre adhesion, as seem in the SEM micrographs. The MFI results showed that the viscosity increases with fibre addition.
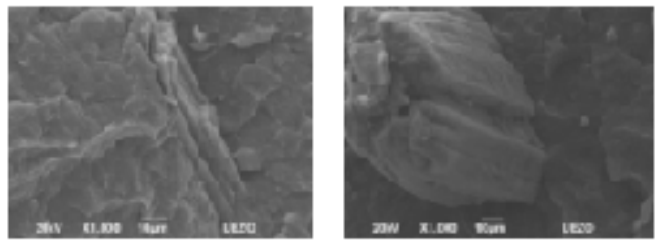

(ys/s)

(90:10) 


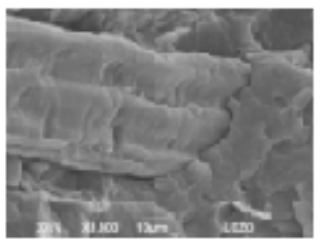

$(80 / 20)$

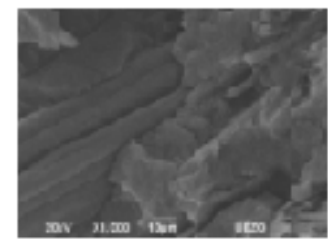

$(70 / 30)$
Figure 3. Micrographs Obtained by SEM for rPP and Composites.

Table 3. Density, Shore D Hardness and MFI of Composites.

\begin{tabular}{llll}
\hline $\begin{array}{l}\text { Sample } \\
\text { (rPP/Fibres) }\end{array}$ & $\begin{array}{l}\text { Density } \\
\text { (g.cm }^{-3} \text { ) }\end{array}$ & $\begin{array}{l}\text { Shore D } \\
\text { Hardness }\end{array}$ & $\begin{array}{l}\text { MFI } \\
(\mathrm{g} / \mathbf{1 0 m i n} \text { ) }\end{array}$ \\
\hline $100 / 0$ & $0.758 \pm 0.069$ & $66.2 \pm 2.9$ & $5.76 \pm 0.03$ \\
$95 / 5$ & $0.894 \pm 0.065$ & $61.2 \pm 1.8$ & $3.72 \pm 0.02$ \\
$90 / 10$ & $0.936 \pm 0.036$ & $62.4 \pm 2.3$ & $2.40 \pm 0.01$ \\
$80 / 20$ & $0.817 \pm 0.140$ & $64.0 \pm 1.2$ & $2.04 \pm 0.01$ \\
$70 / 30$ & $0.909 \pm 0.068$ & $63.8 \pm 1.5$ & $1.62 \pm 0.01$ \\
\hline
\end{tabular}

\section{CONCLUSIONS}

The FTIR analysis revealed that ester bonds are present on the fibre treated surface. It was also shown that the crystallinity and thermal stability of fibres increased slightly after esterification. The composites showed slight reduction in density and hardness in comparison with rPP. The MFI was significantly reduced with rising amount of fibres. The SEM results revealed high matrix/fibre adhesion for composites prepared with up to $30 \%$ fibres, showing good potential use for these materials.

\section{ACKNOWLEGMENTS}

The authors would like to thanks to FAPERJ for financial support.

\section{REFERENCES}

VENKATESHWARAN, N. AND ELAYAPERUMAL, A. 2010. Banana Fiber Composites - A review. Journal of Reinforced Plastics Composites. 29: 2387-2396.
SPINACÉ, M.A.S AND DE PAOLI, M.A. 2000. A tecnología da reciclagem de polímeros. Química Nova. 28 (1): 65-72.

AWAL, A., CESCUTti, G., GOSH, S.B. AND MUSSIG, J. 2011. Interfacial studies of natural fibre/polypropilene composites using single fibre fragmentation test (SFFT). Composites Part A: Applied Science and Manufacturing. 42(1): 50-56.

TSERKI, V., ZAFEIROPOULOS, N.E., SIMON, F. AND PANAYIOTOU, C. 2005. A study of the effect of acetylation and propionylation Surface treatments on natural fibres. Composites Part A: Applied Science and Manufacturing. 36 (8): 1110-1118.

SGRICCIA, N., HAWLEY, M.C. AND MISRA, M. 2008. Characterization of natural fiber surfaces and natural fiber composites. Composites Part A: Applied Science and Manufacturing. 39 (10): 1632-1637.

TANOBEA, V.O.A., SYDENSTRICKERA, T.H.D., MUNAROB, M. AND AMICOA, S.C. 2005. A comprehensive characterization of chemicallytreatedBraziliansponge-gourds(Luffa Cylindrica). Polymer Testing. 24(4): 474-482.

RONG, M.Z., ZHANG, M.Q., LIU, Y., YANG, G.C. AND ZENG, H.M. 2001. The effect of fiber treatment on the mechanical properties of unidirectional sisal-reinforced epoxy composites. Composites Science and Technology. 61 (10): 1437-1447.

CHATTOPADHYAY, S.K., KHANDAL, R.K., UPPALURI, R. AND GHOSHAL, A.K. 2010. Mechanical, Thermal, and Morphological properties of maleic anhydrideg-polypropylene compatibilized and chemically modified banana-fiber reinforced polypropylene composites. Journal of Applied Polymer Science. 117 (3): 1731-1740. 